\title{
THE MOBILE WORKER AND THE ORGANIZATION
}

\author{
James Sena, California Polytechical University, jsena@ calpoly.edu
}

\begin{abstract}
This paper explores the changing environment of the corporation -- the process of change that comes about with the emergence of the mobile worker. They work in a variety of work settings and businesses with varying degrees of virtuality and mobility. The roles and composition of the mobile work force is delineated and investigated; and, the need for corporate oversight, security and governance are discussed.
\end{abstract}

\section{INTRODUCTION}

Today work is becoming less defined as a place where one goes to, and is more defined by what one does. There has been a rapid shift in workplace dynamics with workers outside the traditional office boundaries. The increase in the number of remote workers and the trend for individuals to work on-thego requires the need to be connected and to interact with business-critical information wherever one is whether it's visiting customers, tele-working, or accessing information in the manufacturing plant about customer orders or product performance.

At the tip of the ice berg organizations are feeling the pressure to allow users to access sensitive corporate data via their personal mobile phones. Employees want the flexibility to use applications such as enterprise resource planning (ERP), customer relationship management (CRM), e-mail and instant messaging not only from within the workplace, but at any time from any device. With so much at stake, including network security and customer privacy the organization needs to cautiously address these new and changing requirements [1]. Already organizations of all sizes are taking advantage of anytime, anywhere access; Web services; and social networking features to boost employee collaboration, improve customer service and speed decision-making -- providing the organization's competitive edge. Like previous technology waves, these personal devices are actually a godsend for productivity and collaboration.

The need to adapt and change - be nimble but substantial, adaptive but established, long-lived but perpetually young defines the corporation of the now and the future. According to Michael Malone [2] in his book, The Future Arrived Yesterday: The Rise of the Protean Corporation, such a company will be able to adapt and change themselves at lightning speed. They are the shape-shifters. Most modern companies have learned to incorporate Moore's Law (processing power doubling every eighteen to twenty-four months) and Metcalf's Law of networks (the network grows exponentially with the number of participants). Malone views the corporation using people-oriented management as a competitive advantage. The world of work has changed as new technological innovations -- the PC, the Web, cell phones, online communities, smartphones, etc -arrive at an ever faster rate. As users become more adept in utilizing computing resources in their private lives, they tend to demand more from their business resources as well. This concept, referred to as "consumerization" reflects upon the changing expectations that users place on workplace technology resources [3].

Technology, computers, the Internet, and the World Wide Web are an accepted part of survival and success in the business world. This means that organizations must exist and function competitively and profitably in the virtual world of cyberspace [4]. Currently more people in the world have mobile phones than land lines. Mobile devices outnumber personal computers by three to one, credit cards by two to one and TVs by two to one. IBM's Institute for Business Value predicts that the number of mobile Internet users will reach a billion by 2011 [5].

\section{THE ORGANIZATION}

An organization is a collective group of people who work toward a common goal or purpose. Organizations are unique because they facilitate the performance of tasks that would not ordinarily be within the reach of single participants. Efficient and effective performance levels in an organization translate into the success or failure of the organization. Organizations influence, economically impact, and serve the surrounding community. In summary, organizations often start from an image and become a machine built for accomplishing goals 
either as a small society with a social structure and culture or as an organism making its way through a resource environment [6][7].

\section{The Process of Change}

Organizations that are proactive and ready to change are learning organizations [8][9]. Senge [10] argued that the successful organization of the future is the learning organization -- one that is "continually expanding its capacity to create its future" According to Senge, in a learning organization, adaptive learning is in response to change, whereas generative learning "enhances our capacity to create." Learning is the answer to change. Change has mutated to echange, precipitated by technology, computers, the Internet and the World Wide Web [3]. The Internet is:

An interconnected network of thousands of
networks and millions of computers
(sometimes called host computers or just
hosts) linking businesses, educational
institutions, government agencies, and
individuals... The word Internet is derived
from the word internetwork, or the
connecting together of two or more
computer networks [11].

Every organization has a distinct threshold for absorbing change. This threshold ultimately determines the pace at which many initiatives can be implelemented and accepted. When considering the mobile worker both IT and the organization at large needs to understand the supply and demand of change and anticipate appropriately. To be a successful enabler the organization and the IT function must achieve a balance between tolerance and need for change. Two trends are a part of this happening. First the "wired" worker has become untethered from the traditional office. The transformation began with telecommuting and has progressed to every facet of the workforce. In addition, virtual work teams are dispersed throughout offices and laboratories in every time zone. They meet online via satellite video links, exchange ideas, hold meetings and jointly develop projects. In the modern virtual global corporation work is continuous $-24 / 7 / 365$ [11].

Over the past decade, the number of workers who spend a significant portion of their time and in many cases all their time, away from traditional assigned office space has substantially increased [12]. Mobile workers are now able to do their jobs without being tied to one desk for a fixed period of time. Recently, technology allows employees to work flexibly and improve their work-life choices by working whenever and wherever they need. With work no longer a "place" where one receives pertinent business information and remains productive, the trend towards a larger mobile or remote workforce is even more of a reality. Advances in mobileaccessible technology, from more sophisticated devices with increased processing power to business intelligence software, enable a more productive workforce by pushing the boundaries of what can be accomplished "on-the-go." No longer does location mean restricted access.

\section{The Virtual Corporation}

One characteristic of the high-performance workplace, according to Gartner Research, is the inclusion of ubiquitous collaboration, defined as collaboration anytime, anyplace, and anywhere [13]. Because of its ubiquitous nature, technologies for accomplishing collaborative tasks are of high importance to individuals at all levels and in all types of organizations. While organization leaders frequently focus on cost benefit analysis in choosing technologies for their firms, members of the collaborative work teams may be more impressed with features that aid in efficient and effective task accomplishment. These divergent aims may prevent organizations from achieving maximum efficiency and effectiveness from new technologies [14]. Although collaboration is an increasingly vital feature of business life, companies often promote collaboration indiscriminately. Directive mandates to "just collaborate" create confusion and bottlenecks, diminishing organizational effectiveness [15]. Creating a business case for exploring and creating cooperative workplaces seems to be more fitting. The word cooperative is defined as the engagement in joint economic activity. It also suggests an enterprise may be operated jointly by those who use its facilities or services [16].

In the evolving past and present the term, "virtual organization," does not have a consistent meaning. Generally, production processes transcend the boundaries of a single firm, and as a result, are not controlled by a single organizational hierarchy (see Table 1). As a result, production processes have become more flexible, with different parties involved at different times. The parties involved in the production of a single product are often geographically dispersed. And finally, given geographic dispersion, coordination is heavily dependent on telecommunications and data networks 
rather than physical travel, at least for the people

involved.

\begin{tabular}{|l|l|l|l|}
\hline \multicolumn{2}{|l|}{ INTER (Between Organizations) } & INTRA (Within Organizations) \\
\hline Companies & $\begin{array}{l}\text { People work for many different } \\
\text { companies }\end{array}$ & $\begin{array}{l}\text { Teams } \\
\text { seople work on multiple teams. Reporting } \\
\text { day-to-day working relationships are } \\
\text { matrixed. }\end{array}$ \\
\hline Jobs & $\begin{array}{l}\text { People change jobs with much } \\
\text { greater frequency }\end{array}$ & $\begin{array}{l}\text { Locations } \\
\text { Careers }\end{array}$ & $\begin{array}{l}\text { People acquire additional skills } \\
\text { and experiences to enter new freq sites and working locations } \\
\text { fields, industries, and professions }\end{array}$ \\
\hline
\end{tabular}

Table 1.Virtual Organizations: a beginning framework

For most firms, being virtual is a matter of degree. The production of any complex good or service requires combining various raw materials and modifying them in many stages, with each step adding value as the product wends its way towards the final consumer. At one extreme, a firm is virtual to the extent that each of these steps is performed outside the core firm's boundaries, with the firm acting as coordinator. Some publishing operations approach this extreme, with no writing, editing, printing, and distribution done within the firm itself. But this non-value-adding structure will rarely arise in competitive business environments.

\section{THE MOBILE WORKER}

As organizations stretch their wings and adjust to operate in a world without boundaries management must take steps to eliminate the distance between data centers and remote and mobile workforces. Access to business-critical applications and data, while maintaining a secure environment, is critical the structure of the traditional work environment is continuously changing. Existing work practices and managerial strategies are often not appropriate in those environments. In particular, traditional office communication with coworkers and management, usually dependent on physical proximity, has been disrupted [17].

According to IDC [13] the U.S. mobile workforce is expected to grow to $73 \%$ of the total U.S. workforce in 2011. Across the world $30.4 \%$ of the workforce will be mobile in 2011. This statistic presents a challenging portrayal - the mobile workforce will be the norm not the exception. There are multiple perspectives and delineations of the mobile worker. Based on the IDC Research Services survey, 39 percent of the respondents said they are deploying mobile applications with more consumer-like functionality, such as social media and Web 2.0 services, than in the past. Just over 25 percent are designing mobile applications that take greater advantage of native device capabilities such as cameras and GPS. A quarter of the respondents are shifting away from packaged applications to rely on custom-developed mobile applications that support these features. For instance, if during a customer meeting, a salesperson is asked about a product road map he is unfamiliar with, he can use social networking to quickly find answers. He can tag the question to find a subject matter expert, check that person's availability and immediately incorporate that person into the conversation. By responding so quickly, he is able to keep the customer engaged and hopefully close the sale [1].

Nearly a third of the respondents (32 percent) currently use handheld mobility technology in their daily job. Another 39 percent expect to use them in their daily jobs within the next 12 to 18 months In the study, 35 percent of the respondents said all groups in the organization are putting pressure on IT to adopt handheld mobility solutions. With such a diverse base of users, it's not surprising that 59 percent of those surveyed agreed that their organization found it important to support multiple mobile handheld device types. And, 59 percent agreed that their organization found it important to support personal handheld devices.

While teleworking and remote-access are becoming increasingly the norm, the majority of business applications and the critical customer data contained within them still remain cordoned inside the four walls of the enterprise. Once field workers leave the office they become isolated from vital customer information and desk-bound enterprise applications lose their immediate value. At a corporate level 
mobile business applications play an integral part of increasing customer satisfaction levels and meeting increasingly stringent service level agreements in a competitive marketplace [18].

Field force mobilization increases the efficiency of office-based staff - spends less time talking to workers in the field on mobile phones allowing them to deal with other work-related issues. The mobile workers experience a streamlined workflow, less paperwork and have immediate access to accurate information enabling them to conduct work in a shorter period of time. At a business level, direct wireless integration with corporate applications gives managers real-time information for monitoring and managing a geographically-dispersed workforce. This single-system integration can also be used to trigger back-end fulfillment processes, such as immediate invoice generation to improve cash flow or real-time order processing which will speed up deliver times [19].

As mobile computing has become more ubiquitous, user-centric computing scenarios have evolved out of the necessity to give users access to the resources they need, when they need them. This introduces significant complexity for IT organizations because each user type or usage scenario has different computing requirements and must be managed differently, as shown in Table 2.

\begin{tabular}{|c|c|}
\hline Worker Category & Description \\
\hline $\begin{array}{l}\text { Office } \\
\text { Knowledge }\end{array}$ & $\begin{array}{l}\text { generally work from a local dedicated PC running a variety of productivity applications. The } \\
\text { IT challenge is to deliver a personalized experience that ensures high productivity levels. In } \\
\text { addition, office hoteling (sharing one office among multiple users, divided up by times of the } \\
\text { day) introduces the challenges of a single machine serving multiple user profiles, } \\
\text { requirements, and applications }\end{array}$ \\
\hline $\begin{array}{l}\text { Mobile } \\
\text { Knowledge }\end{array}$ & $\begin{array}{l}\text { - require secure access to business-critical applications and other corporate resources via a } \\
\text { variety of environments and devices, from wherever they are. IT departments face the } \\
\text { challenge of providing the flexibility that these users need while ensuring that data security is } \\
\text { not compromised. In addition, IT must have a means to maximize worker productivity while } \\
\text { minimizing the risk of unauthorized access to corporate data in the event of a lost or stolen } \\
\text { device }\end{array}$ \\
\hline $\begin{array}{l}\text { Contract and } \\
\text { Offshore }\end{array}$ & $\begin{array}{l}\text { need access to corporate computing resources, yet often fall under different security } \\
\text { constraints, compliance policies and often bandwidth limitations than full time workers. } \\
\text { Compliance requirements alone may necessitate partitioning of outsourced workers from the } \\
\text { day-to-day access that full time users enjoy. Those stipulations, whether driven by legal } \\
\text { requirements or organizational policy, present a significant challenge to IT professionals }\end{array}$ \\
\hline Task & $\begin{array}{l}\text { such as call center employees, warehouse workers, and retail employees, typically require } \\
\text { one or just a few applications to get their jobs done. These users typically don't have a } \\
\text { dedicated workstation. Instead, they must be able to access their applications from any } \\
\text { computer in their workplace. IT organizations need a solution that enables them to deliver } \\
\text { only the required applications that task workers can securely share on multiple devices in the } \\
\text { organization }\end{array}$ \\
\hline Remote & $\begin{array}{l}\text { effectively have the same requirements as knowledge workers, but must be managed } \\
\text { differently as these users often work outside the corporate firewall. IT departments need a } \\
\text { way to provide them with secure access to their work environment through a single, } \\
\text { controlled access point. Today's worker usually does not care how application delivery } \\
\text { occurs, as long as it is painless, seamless and functional. The challenge for IT organizations is } \\
\text { to deliver a consistent, quality experience that enables all users, regardless of their type, } \\
\text { location or device, to get their jobs done, while minimizing the cost and effort of managing } \\
\text { that experience. At the same time, security must be maintained at all times, for all user types. }\end{array}$ \\
\hline
\end{tabular}

Table 2. User Centric Computing Scenarios

The definition of a mobile worker varies -- Clevanger [20] provides a common framework for discussion by incorporating three different categories of mobile workers: the constantly-mobile worker, the occasionally-mobile worker, and the hybrid-mobile worker (as shown in Table 3). 


\begin{tabular}{|l|l|}
\hline Worker Category & Description \\
\hline Constantly Mobile & $\begin{array}{l}\text { do the job while moving; usually task-oriented -- need ability to automate tasks by } \\
\text { capturing, analyzing and displaying data (handheld device) }\end{array}$ \\
\hline Occasionally Mobile & $\begin{array}{l}\text { travel between locations - but only do work while at destination -- not moving; usually } \\
\text { information oriented -- they are mobile (requires laptops) }\end{array}$ \\
\hline Hybrid Mobile & $\begin{array}{l}\text { need to be able to access information while on the go -- instead of waiting until they get } \\
\text { to their destination -- unique in that they need two devices -- one optimized for } \\
\text { stationary work (laptop) and another for work in motion Smartphone) }\end{array}$ \\
\hline
\end{tabular}

Table 3. Categories of Mobile Workers

Types of outputs are typical of mobile workers: when working from their home base, mobile workers responded that their primarily work tasks were computer-based teamwork and correspondence; creative thinking; planning/scheduling/coordinating; phone conversations; learning, research, and writing; creating presentations; and reading. When working at their traditional office location, mobile workers responded that their work tasks were the same tasks performed at home, with the addition of face-to-face meetings (face-to-face meetings 77 percent at primary location vs. 4 percent at home). When working from other locations, mobile workers responded that their work tasks were mainly face-toface meetings and e-mail processing [21].
The definition of "mobile worker" can also vary widely from one industry to another, and between experts within those industries. Because of this, there is a need to establish a common understanding. Mobile technology is evolving rapidly and changing the way the enterprise functions. With this evolution, the definition of "mobility" and "mobile worker" will changes. Figure 1 provides a set of two tables and a progressive Venn diagram that relates worker roles and worker types roles vary from simple data entry to knowledge and information dissemination and handling.

\begin{tabular}{|l|l|}
\hline Worker Role [1] & Tasks \\
\hline Data Entry & Create and consume data \\
\hline Task & Create, transform, manipulate and consume data \\
\hline Information & $\begin{array}{l}\text { Owner of data relationships and information. Analyzes and } \\
\text { transforms content, develops knowledge, collaborates and } \\
\text { overseas data handling processes }\end{array}$ \\
\hline Knowledge & $\begin{array}{l}\text { Owns and analyzes knowledge and ideas. Typically leads and } \\
\text { direct business processes and collaborates with other knowledge } \\
\text { workers }\end{array}$ \\
\hline
\end{tabular}

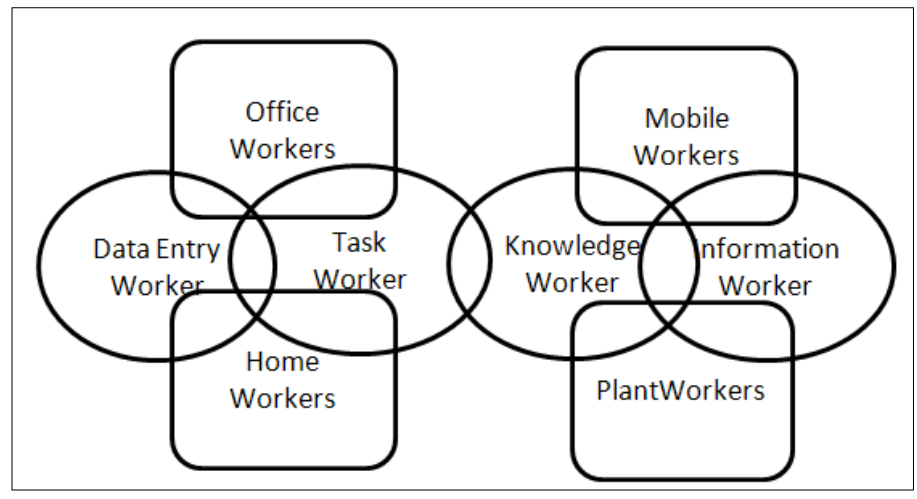




\begin{tabular}{|l|l|}
\hline Worker Type [1] & Tasks \\
\hline Office & $\begin{array}{l}\text { performs tasks from a fixed internal location; utilizes multiple } \\
\text { applications and data sources }\end{array}$ \\
\hline Mobile & $\begin{array}{l}\text { performs tasks from various internal and external locations; } \\
\text { utilizes multiple applications and data sources }\end{array}$ \\
\hline Home-based & $\begin{array}{l}\text { performs tasks from a fixed external location; utilizes multiple } \\
\text { applications and data sources }\end{array}$ \\
\hline Factory-Plant & $\begin{array}{l}\text { performs tasks from a fixed internal location; utilizes fixed set of } \\
\text { applications }\end{array}$ \\
\hline
\end{tabular}

Figure 1. Worker Roles vs Worker Types

Mobile workers depend upon a web of relationships (i.e. a network) to fulfill their tasks. Astute managers today, however, are paying attention to both the formal and informal organization networks [22][23][24][25]. Workers seek to be effective in the different purposeful, value-creating networks to which they belong [26]. A value network is any web of relationships that generates economic or social value through complex dynamic exchanges of both tangible and intangible benefit. Such networks operate internally across the organization and also extend externally to partners, stakeholders, and the industry [27].

Mobile workers need space on demand; supplies; technical support and training; and places to send mail and to meet and socialize with colleagues, customers, and clients. Social or organizational network analysis can be used to improve knowledge flows and locate expertise by focusing on individual communication flows. Value network analysis can help employers to better support key roles and organize projects and activities that cross internal and external boundaries. Providing the necessary infrastructure by evaluating mobile worker roles creates new business opportunities for infrastructure and technology providers and transforms the provision of space and services [16].

\section{ORGANIZATIONAL IMPLICATIONS}

Many companies have issued laptops as the standard PC, a strategy that undercuts security. Perhaps only employees who need to work while traveling should be issued laptops; examples include senior executives, salespeople, auditors, field technicians, some marketing staff and telecommuters. The rest might instead use PCs or computers at home or at satellite offices. Until software vendors have appropriate tools to cover the risks associated with mobile devices the organization will need to set policies banning or at least discouraging their use. Not only does work vary by type but also by the size of the organization. Table 4 shows the percent of mobile workers by travel pattern [27]. Small businesses tend to do more local travelling while larger businesses rely on mobility throughout the organization.

\begin{tabular}{|l|l|l|l|}
\hline & $\begin{array}{l}\text { Medium } \\
\text { Business }\end{array}$ & Small Business & $\begin{array}{l}\text { Very small } \\
\text { Business }\end{array}$ \\
\hline Interoffice Mobile & $33 \%$ & $31 \%$ & $17 \%$ \\
\hline Local travel/field workers & $27 \%$ & $35 \%$ & $43 \%$ \\
\hline Long-distance travel & $22 \%$ & $19 \%$ & $15 \%$ \\
\hline Telecommuters & $18 \%$ & $15 \%$ & $25 \%$ \\
\hline
\end{tabular}

Table 4. Travel Pattern related to Size of Organization.

Virtual application delivery throughout the enterprise streamlines many organizational imperatives. Table 5 shows mobile application usage [28]. Some of the key areas where virtualized applications can make a difference are apparent from a time perspective. Planned or unplanned, system outages can cripple productivity when key business applications aren't readily available. Virtual and network-based delivery enables workers to access their applications from any Web-enabled device as though it's business as usual. With multi-site deployments, users are transparently redirected to an available site, if necessary. All the 
while, valuable business information remains protected.

\begin{tabular}{|l|l|}
\hline Mobile Applications Usage [28] & Percent Access \\
\hline eMail ,PIM, Calendar/contacts & $88 \%$ \\
\hline General web browsing & $88 \%$ \\
\hline Productivity software & $76 \%$ \\
\hline Network and systems management & $60 \%$ \\
\hline CRM/sales force automation & $58 \%$ \\
\hline Printing, faxing/document management & $54 \%$ \\
\hline Help desk application & $54 \%$ \\
\hline Business Intelligence Applications & $54 \%$ \\
\hline Time and Billing & $49 \%$ \\
\hline Enhanced collaboration/messaging & $46 \%$ \\
\hline ERP/Supply Chain Management & $40 \%$ \\
\hline Engineering/software development & $39 \%$ \\
\hline Location-based services & $39 \%$ \\
\hline Games and Entertainment & $19 \%$ \\
\hline Healthcare/pharmaceutical applications & $16 \%$ \\
\hline Real estate applications & $4 \%$ \\
\hline Law Enforcement/Public safety applications & $3 \%$ \\
\hline Other & $1 \%$ \\
\hline
\end{tabular}

Table 5. Mobile Application Usage

As mobile workforces grow, the demands on organizations to provide tools allowing employees to access key organizational data anytime, anywhere is growing [28]. Organizations are incorporating mobile strategies into their IT infrastructure plans. According to Forrester Research [29], providing mobility support to employees is a top telecommunications and IT initiative of today's enterprises. In addition, Forrester states that nearly half of enterprises say that formalizing and executing on a mobile strategy (one which contains architectural frameworks for mobility) is a priority.

Cooperative innovation projects between manufacturers and users are complex and benefit from an innovation approach that clearly defines the roles and responsibilities of each participant. Some lessons can be learned from recent co-constructive developments; however, these lessons are largely based on single organizational contexts, non-mobile computing devices and a dialogue between innovators and users in fixed-location settings. Since mobile settings and technologies span time and location challenge the interaction inherent in nonmobile contexts, manufacturers and innovators need to support an interactive innovation for mobile environments [30].

According to Oliver [31] seventy per cent of enterprise data exists in various mobile settings, from laptops to smartphones, to retail and remote office environments. The sheer size and complexity of today's enterprises makes it difficult to respond to the rate of change in IT security, requiring a top-down strategy that prioritizes risk and accepts the limitations of available technologies. Only through the adoption of high-level policies and controls aimed at fostering flexible security practices across the organization and via more aggressive sharing of information about threats with other, their partners, the supply chain, and the customer interface can companies effectively improve their protection and continue to do business as usual. Considering the challenges of mobility Oliver [31] in Table 6 compares the advantages of networked computers with the challenges of mobile devices. 


\begin{tabular}{|l|l|}
\hline Networked Computers & Mobile Devices \\
\hline Unlimited bandwidth & Bandwidth is limited \\
\hline Guaranteed, reliable connectivity & Intermittent, unreliable connectivity \\
\hline Local Support for Users & No Local Technical Support \\
\hline IT can easily get to systems & IT may never see devices \\
\hline The same platform is used & A variety of devices and platforms \\
\hline Physical building security & Easily lost or stolen \\
\hline
\end{tabular}

Table 6. Comparing Networked Computers with Mobile Devices

Unreliable networks and lack of communication are not the only problems for mobile workers and the organization. A report by business communications company Avaya found that more than half of mobile device users missed important business meetings, customer inquiries, or business leads due to failed communications. More than one-third said missed communications directly resulted in lost revenue or additional expenses. And while two-thirds carry more than one mobile device every day, most pick up messages at night because they cannot be reached in a timely manner [32].

Unfortunately, the concepts of the traveling worker versus the mobile worker can be confusing when it comes to managing desktop experiences. The traveling worker requires access to network resources from a remote location while the mobile worker may start the day accessing applications from his or her home desktop, later login using a mobile device from a customer site, then visit the office to conduct a Microsoft Live Meeting, before finally completing a last minute order using a web terminal at an Internet café late at night. While few users will have all of these experiences in one day, it is a reality that many IT professionals must support this range of user experiences, while at the same time ensuring regulatory or internal policy compliance, security, and a satisfactory user experience. With these dynamic desktop environments, IT departments face three main challenges as they seek to deploy, manage and secure [3].

- Delivering the applications, data and resources to a range of user types and a variety of access methods;

- Effectively managing the infrastructures needed to meet these requirements while delivering an optimized user experience; and

- Maintaining security and an increasing range of user types and access requirements
In the past, most users were very predictable to manage as they required a static set of applications and worked primarily in the confines of their office

Mobile workers are key to an organization's success. Their device usage varies broadly. For example, information workers need to be able to use their devices to send email, open PDFs and schedule meetings on the go. By contrast, task workers need access to the most up-to-date customer information, and require fast approval to go ahead with business processes such as work orders. To add to this complexity, the number of devices that support these workers are proliferating throughout corporations.

With a mobile workforce comes the widespread distribution of sensitive, proprietary, and core data outside the secure walls of the organization. A successful mobile deployment needs to have measures in place to control and protect mobile assets [33]. The bandwidth a mobile worker requires depends on the type of work to be done, and, similarly, the degree of security the device requires depends on the level of access to corporate intranets and sensitive information. In general, the more devices with access to a corporate network, the more likely that security can be comprised. Tradeoffs are required between increased productivity and increased risk. As with general laptop security, handheld best practices fall into two categories: security access to the device itself and network security.

Mobile solutions for enterprises have primarily consisted of personal or business-owned mobile phones deployed on an ad hoc basis that permitted little control by the company. Today's dramatically growing virtual workforce requires alternative tactics to keep workers responsive and productive, to control telephony costs, and ensure security and compliance with regulatory and company requirements. As the 
number of mobile workers increases, the cost to keep them connected to their workplace is one of the fastest-growing components of the IT budget. Determining the correct level of security to protect the organization without impeding usability is important, as is developing the right policies and controls that support it [34].

Corporate policy should limit the amount and type of sensitive information that's storable on a remote laptop or handheld device along with some form of storage-level encryption. At the highest levels of data sensitivity, the policy should entirely prevent data storage on mobile devices. Access to the corporate network via mobile devices must be controlled -several software-based virtual private network (VPN) services provide secure remote access capabilities to corporate networks from laptops.

Managers have a pivotal role to play in helping mobile workers to be as effective as possible, but many fail to understand that they have to adapt their managerial style if they are going to genuinely get the most out of their mobile team [35]. One motivator for mobile workers is trust, not only to make independent decisions, but to manage their time. Micro-managing mobile workers could result in a breakdown in the relationship, combined with increased stress and decreased motivation for the mobile worker. Managers who take time to get to know the world of each of their mobile worker can build a bond that does not come as naturally as for those who share an office.

Simply giving them a mobile phone and laptop and sending them on their way is unlikely to be sufficient to help mobile workers be as productive as possible. In addition to the tailored management style, mobile workers also need to feel connected to the headquarters in a variety of different ways. This can be achieved through ease of picking up emails and messages in a variety of locations as well as having access to colleagues through different media. This

\section{REFERENCES}

1. Sybase. The New Mobile Order: Consumerization of IT Presents a Wealth of Business Opportunities for IT Management. Market Pulse 2010.

2. Malone, M. The Future Arrived Yesterday. Crown Book. 2009 helps not only with isolation, but also supports their need to be flexible when their plans change last minute or they are experiencing difficulties.

Businesses need to assess the right resources based on how mobile their employees are. While occasional mobile workers may only need a mobile phone, a laptop and access to the internal work network, employees who spend most of their time on the road may require a PDA or smartphone or access to video conferencing tools. In order for businesses to capitalize on the benefits of mobile working, they must make an informed decision about the level of technology their workforce requires.

Communication is critical. Regular, informal chats should not only be encouraged between team members, but should also be led by the team manager. Managers that only contact their mobile team members about tasks and projects, without taking the time to discuss their personal well-being, relay latest news from the office or to chat about last night's game, will only increase the sense of isolation.

Intelligence about a business, its processes, products, customers and areas of expertise and knowledge is a major strategic asset for any organization. This essential information can be locked away in the minds of an organization's employees, rather than documented in handbooks, manuals or a wide range of electronic resources. It's important that organizations harness and document information correctly to avoid crucial business knowledge from exiting the company when employees leave -- or not being available when they're working away from the company [36]. The four key steps any business should consider when implementing mobile strategies are: 1. Understand people and processes. 2. Identify the information. 3. Review data capture methods. 4. Assess and evaluate. In conclusion, data is the lifeblood of any organization and it's time businesses stopped overlooking the importance of collecting and sharing knowledge with mobile workers.

3. En Pointe Global Services LLC. Whitepaper\#2 in 4 Part Series. Released 15 January 2010

4. Harrell, G.D. Marketing: Connecting with Customers $\left(2^{\text {nd }}\right.$ ed.). Upper Saddle River, NJ 2002

5. Campbell, Don Mobile Evolution Opens Doors to New Definitions of Work Place, CIO Magazine. January 2009 
6. Scott, W.R., \& Davis, G.F. (2007). Organizations and Organizing: Rational, natural, and open system Perspectives Upper Saddle River, NJ: Pearson

7. Schermerhom, J.R., Jr. Management $\left(9^{\text {th }}\right.$ ed.) Hoboken, NJ. 2008.

8. Bartleby.com The Columbia World of Quotations. Retrieved March 27, 2009 from http://www.barleby.com/66/2/4602.html

9. Kanter, R.M. The Change Masters: Innovation and Entrepreneurship in the American Corporation. New York.

10. Senge, P.M. The Fifth Discipline: The Art and Practice of the Learning Organization. New York: Doubleday. 1990.

11. Laudon, K.D., \& Guerico Traver, C. (2007). E-commerce: Business, technology, society ( $3^{\text {rd }}$ ed.). Upper Saddle River, NJ: Prentice Hall.

12. Lopez, Maribel. (2010) Successful Mobile Deployments Requires Robust Security. Lopez Research LLC. www.lopezresearch.com

13. Anonymous IDC; More Than One Billion Mobile Workers Worldwide by Year's End, According to IDC

14. Barbara Jo, E. Brown, Cynthia S. Deale, Adam T. Hardin, Collaboration Using Cloud Computing and Traditional Systems. Issues in Information Systems, Volume X, No. 2, 2009

15. Cross, R. Parker, A., Prusak, L. and Borgatti, S.P. Knowing what we know; supporting knowledge creation and sharing in social networks, Organizational Dynamics, (2001), Vol. 30, No. 2, pp. 10020.

16. Venezia, Camille and Verna Allee Supporting mobile worker networks: components for effective workplaces. Journal of Corporate Real Estate. London: 2007, Vol. 9, Is 3; pg 168, 15 pgs.
17. Garglulo, Terence. The Ten Top Strategies for Managers of Mobile Workers. Making Stories, et 2010

18. Lawton, Christopher Technology (A Special Report): Mobility - Making the Connection: New products make it wasier for mobile workers to connect to the Internet Wall Street Journal. (Eastern edition). New York, N.Y.: Apr 20, 2009. pg. R.4

19. Wingfield, Nick Technology (A Special Report); Why It May Be Time to Leave the Laptop Behind; For More Mobile Workers, Phone Increasingly Give Them Much Of What They Need -- With a Lot Less Hassle. Wall Street Journal. (Eastern edition). New York, N.Y.: Oct 27, 2008.pg. R.1

20. Clevenger, Nathan, What is a Mobile Worker. Views on Mobility August/September 2008

21. Duggan, Mike Mobilizing Knowledge in an Always on. Knowledge Management Review. Chicago: Mar/Apr 2008. Vol. 11, Is. 1; pg. 24, 4 pgs

22. Evans, P. and Wolf, B. (2005), "Collaboration rules", Harvard Business Review, Vol. 83, pp. 96-104

23. Laycock, M. (2005), "Collaborating to compete: achieving effective knowledge sharing in organizations", The Learning Organization, Vol. 12 No. 6, pp. 523-38.

24. Cross, R. and Parker, A. (2004), The Hidden Power of Social Networks: Understanding How Work Really Gets Done in Organizations, Harvard Business School $\underline{\text { Press, }}$ Cambridge, MA.

25. Allee, V. (2000), "The value evolution: addressing larger implications of an intellectual capital and intangibles perspective", Journal of Intellectual Capital, Vol. 1 No. 1, pp. 17-32.

26. Allee, V. (1997), The Knowledge Evolution: Expanding Organizational Intelligence, Butterworth-Heinemann, Newton, MA.

27. Yankee Group, Fixed Mobile Convergence Survey- SMB, 2007 
28. McDowell. Making Mobility your Business Advantage. CIO Magazine. Customer Solutions Group, 2010

29. Forrester Consulting. Enable your Workforce with True Anytime, Anywhere Connectivity, Qualcomm, Dec 1, 2009

30. Kietzmann, Jan Interactive innovation of technology for mobile work. European Journal of Information Systems. Basingstoke: Jun 2008. Vol. 17, Is. 3; pg. 305, 16 pgs

31. Oliver, Mike. Mobility for Dummies. Sybase: A John Wiley and Sons, Ltd. Publication, 2010
32. Simmons, Robert, Managing a Mobile Workforce. Personnel Today. Sutton: Mar 6, 2007. pg. 26, 2 pgs

33. Chou, Wesley. Considerations for an Efficient Mobile Workforce15209202/08/\$25.00 @ 2008 IEEE Published by the IEEE Computer Society computer.org/ITPro, 2010

34. Yu, Shane Define your mobility strategy Communications News. Nokomis: Jun 2008. Vol. 45, Is. 6; pg. 28, 3 pgs 